\title{
HIBRIDIZAÇÃO IN SITU FLUORESCENTE: PRINCÍPIOS BÁSICOS E PERSPECTIVAS PARA O DIAGNÓSTICO DE DOENÇAS INFECCIOSAS EM MEDICINA VETERINÁRIA
}

\section{S.M.N. Neves; R.M.C. Guedes}

Universidade Federal de Minas Gerais, Escola de Veterinária, Departamento de Clínica, Av. Antônio Carlos, 6627, CEP 31270-901, Belo Horizonte, MG, Brasil. E-mail: guedes@vet.ufmg.br

\section{RESUMO}

\begin{abstract}
Nesse manuscrito são discutidos aspectos relevantes sobre desenvolvimento da técnica de hibridização fluorescente in situ, seus princípios básicos, aplicações e perspectivas em medicina veterinária. Além disso, compara as vantagens e desvantagens em relação às outras técnicas de diagnóstico in situ. A FISH demonstra ser uma técnica com grande potencialidade de uso rotineiro, pois associa agilidade de execução, alta sensibilidade e especificidade e visualização do agente infeccioso viável no tecido.
\end{abstract}

PALAVRAS-CHAVE: Diagnóstico in situ, sonda, rRNA, fluorescência.

\section{ABSTRACT}

FLUORESCENT IN SITU HYBRIDIZATION: BASIC PRINCIPLES AND PERSPECTIVES FOR DIAGNOSING INFECTIOUSDISEASESIN VETERINARY MEDICINE. The present study presents a review of the development of the fluorescent in situ hybridization technique, its basic principles, applications and perspectives in veterinary medicine. It furthermore compares the advantages and disadvantages in relation to other in situ diagnostic techniques. The FISH technique proves to be one with great potential for routine use insofar as it offers speed coupled with high sensitivity and specificity, while providing for the visualization of the infectious agent in tissue.

KEY WORDS: in situ diagnosis, probe, rRNA, fluorescence.

Eficácia e agilidade no diagnóstico sempre foram preocupações de técnicos veterinários a fim de controlar doenças em diversas espécies animais. Além da identificação do agente, o conhecimento da patogenia e a resposta imunológica do hospedeiro são importantes para o direcionamento das ações na prevenção de doenças.

Métodos convencionais de isolamento e identificação de micro-organismos envolvem propagação in vitro do agente que pode apresentar limitações quanto à sensibilidadee especificidade, possibilidade de erros metodológicos, necessidade de cultivos em meios especiais, ou até mesmo estar impossibilitado no caso de agentes não-cultiváveis, tratamentos prévios com antimicrobianos ou presença de microbiota bacteriana competitiva. Além disso, o isolamento pode apresentar riscos a quem executa essa tarefa pela característica zoonótica de alguns micro-organismos. Outro empecilho relacionado aos métodos convencionais refere-se às dificuldades de recebimento das amostras em prazo adequado para isolamento devido às grandes distâncias e transporte dificultado pela necessidade de conservação do material, especialmente para exames bacteriológicos, que não devem ultrapassar 24 horas até a chegada ao laboratório (Wolcot, 1992; Boye et al., 2006).

Técnicas baseadas na reação em cadeia da polimerase (PCR) facilitaram a detecção rápida e sensível de bactérias independente de serem ou não cultiváveis. No entanto, estas técnicas não oferecem informações sobre a distribuição espacial dos microorganismos no tecido ou sua associação com a lesão. As provas sorológicas também ocuparam lugar de destaque no diagnóstico de doenças, porém, podem não diferenciar resposta imune vacinal e infecciosa, não são capazes de detectar anticorpos em estágios iniciais da doença, além de apresentarem a mesma desvantagem da PCR sobre a distribuição do agente no organismo hospedeiro (AMANn et al., 2001).

Como alternativa aos exames bacteriológicos tradicionais, vários métodos de diagnóstico in situ, utilizando anticorpos ou sondas de oligonucleotídeos, estão sendo desenvolvidos para detecção de patógenos específicos (AMANn et al., 2001; BOYE et al., 2006).

Hibridização fluorescente in situ (FISH) é um método histoquímico que permite a visualização, identificação, enumeração e localização simultânea 
de micro-organismos in situ, sem a necessidade de cultivos celulares. É um método que consiste na visualização direta em microscópios óticos epifluorescentes em cortes histológicos. Também permite que sequências deácidos nucleicos sejam examinadas no interior de células sem alterar sua morfologia ou integridade de seus compartimentos. Com isso, há a combinação da precisão da genética molecular com a informação visual do microscópio ótico (MOTER; Gobel, 2000; Ploeg, 2000; Amann; Fuchs, 2008).

As duas principais vantagens de FISH sobre a imuno-histoquímica são a maior facilidade de sintetizar sondas específicas marcadas do que produzir anticorpos monoclonais ou policlonais e a possibilidade de detectar somente bactérias viáveis, nos tecidos no momento da fixação.

Comparando ainda a FISH com a imuno-histoquímica, a FISH tem a vantagem de ser mais específica e sensível, sem sofrer influência da grande variação de sensibilidade e especificidade entre os kits e anticorpos comerciais disponíveis, além dos erros de fixação e processamento do tecido que podem levar a resultados equivocados na imuno-histoquímica, com marcações inespecíficas ou falso-negativos. No entanto, a FISH tem a desvantagem de necessitar de equipamentos modernos e dispendiosos, como microscópio com filtros epifluorescentes e, além disto, as preparações não serem permanentes, necessitando, portanto, de outras ferramentas de registro de imagem (Sur et al., 2009).

No intuito de apresentar uma nova ferramenta de diagnóstico de doenças infecciosas e estudos patogênicos, esse trabalho irá revisar a técnica de FISH e suas possíveis aplicações na medicina veterinária.

\section{HISTÓRICO}

A primeira técnica histoquímica consistia em marcar estruturas celulares ou acúmulos celulares com marcadores naturais ou sintéticos. Geralmente, esses marcadores não eram específicos por terem afinidade com várias categorias moleculares como lipídeos, carboidratos, ácidos nucleicos e proteínas (LEVSKY; SINGER, 2003). Ainda, segundo esses mesmos autores, na década de 1940, demonstraram-se que anticorpos conjugados com fluorocromos ligavamse aos epitopos sem perderem a especificidade. Em 1977, RUDKIN; STOLLAR conseguiram detectar ácidos nucleicoshibridizados com anticorpos marcados com fluorocromos, porém, essa técnica foi substituída pelo advento das sondas fluorescentes.

Após a descoberta de que moléculas de RNA conseguiam o anelamento com sequências complementares de DNA ou RNA para formar híbridos DNA-RNA e RNA-RNA, biólogos começaram a considerar a possibilidade da hibridização em preparos intracelulares de DNA-RNA. A hibridização é uma reação muito dinâmica em que uma sequência alvo desnaturada e uma sonda de fita simples de DNA ou RNA complementar formam um híbrido estável pela ação do calor (SWINGER; TUCKER, 1996).

Em 1969, GALL; PARDUE desenvolveram a primeira técnica de hibridização in situ utilizando sondas marcadas com radioisótopos. Os procedimentos experimentais necessitavam de longos períodos de exposição para produzir sinais mensuráveis nos filmes radiográficos, deixando o processo lento. Além disso, as sondas eram dispendiosas, necessitavam de manuseio, transporte e estocagem de acordo com regulamentações restritas, e, apesar de terem boa sensibilidade, havia limitações em relação à resolução da imagem (PlOEG, 2000).

A introdução da FISH, primeiramente desenvolvida por BAUMAN et al. (1980), proporcionou um aumento significativo da resolução, rapidez e segurança. Contribuiu mais tarde para desenvolvimento da detecção simultânea de múltiplos alvos e a quantificação de microrganismos em um único procedimento, tornando-se rapidamente numa tecnologia aplicada tanto na biologia quanto na citogenética (Ploeg, 2000; Levski; Singer, 2003).

\section{PRINCÍPIOS BÁSICOS}

No procedimento histoquímico da FISH, o princípio básico é o anelamento da sonda com a sequência alvo, para a visualização em microscópio epifluorescente. Entende-se por sonda, uma sequência de oligonucleotídeos complementares e específicos marcados com substâncias fluorescentes os quais se anelarão ao alvo. Há duas possíveis marcações das sondas, a direta e a indireta. O processo mais utilizado, por ser mais rápido e de fácil execução, é a marcação direta. Um ou mais fluorocromos são diretamente conjugados às sondas que se ligam nas regiões 5' ou 3' do alvo. A marcação indireta pode aumentar a sensibilidade ligando uma molécula de digoxigenina à sonda. Em etapa subsequente, ocorre ligação de anticorpo conjugado com fluorocromo a esta digoxigenina. Processo alternativo à técnica indireta seria a utilização de amplificação do sinal por reação enzimática, usando peroxidase em substituição ao fluorocromo (Moter; Gobel 2000; PLOEG, 2000), semelhante às etapas finais de uma coloração por imuno-histoquímica. (Moter; Gobel, 2000).

De acordo com BOtari et al. (2006), a FISH tem quatro procedimentos básicos: 1) fixação e permeabilização da amostra, 2) hibridização, 3) lavagem para remoção das sondas em excesso e 4) detecção pela microscopia fluorescente (Fig. 1). Antes da hibridização, as amostras contendo os micro-organismos são fixadas para proteger o RNA da degradação de RNAses endógenas e permeabilizadas para permitir queas sondas penetrem na célula (MOTER; GOBEL, 2000). 

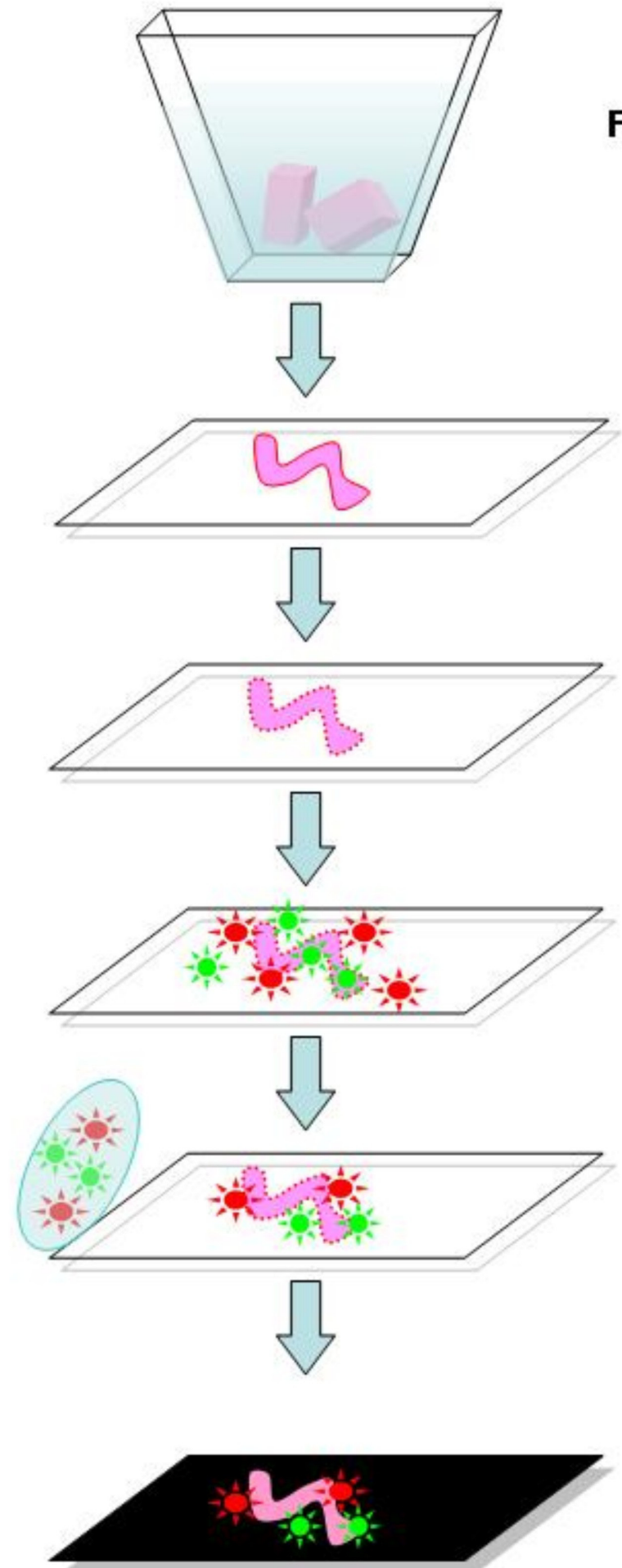

Fig. 1 - Principais etapas da hibridização fluorescente in situ.

\section{Fixaçāo do tecido}

\section{Pemeabiizaçāo da amostra}

\section{Hibridizaçāo}

\section{Lavagem do excesso de sondas}

\section{Visualizaçāo}

\section{Preparaçāo da lâmina}

A maioria das aplicações da FISH tem como alvo o RNA ribossomal. A utilização deste alvo justifica-se primeiramente por todas as células necessitarem de ribossomos para a translação, portanto, podem estar presentes em todas as células vivas (AMANN; Fuchs, 2008). A segunda razão é a sequência do rRNA ser evolutivamente conservada em relação a outras sequências de genes dentro de uma mesma espécie, não sendo possível desenhar uma sonda para identificar grandes domínios taxonômicos como filos, classes ou ordens. A terceira e última razão é, como cada célula contém muitos ribossomos, esse alvo é naturalmente amplificado podendo atingir um número de 100.000 cópias por célula (AMANN et al., 2001; AMANN; Fuchs, 2008). 
Tabela 1- Fluorocromos mais utilizados na deteç̧ão de micro-organismos e seus respectivos comprimentos de onda.

\begin{tabular}{lccl}
\hline \multirow{2}{*}{ Fluorocromo* } & \multicolumn{2}{c}{ Comprimento de onda (nm) } & Cor \\
\cline { 2 - 4 } & Excitação & Emissão & Verde \\
\hline FITC & 492 & 528 & Verde \\
FluoXE & 488 & 520 & Vermelho \\
TRITC & 557 & 576 & Vermelho \\
TexasRed@ & 578 & 600 & Laranja/vermelho \\
Cy3 & 550 & 570 & infravermelho \\
Cy5 & 651 & 674 & \\
\hline
\end{tabular}

${ }^{*}$ FITC - Fluorescein-Isothiocyanate; FluoXE - 5-(-6-) carboxyfluorescein- $N$ - hydroxysuccimide-ester; TRITC - Tetramethyl-Rhodamine-Isothiocyanate; Cy3 e Cy5 - Cianinas 3 e 5.

Fonte: (adaptado) Cullander, 1999; Moter; Gobel, 2000.

\section{SONDAS}

As sondas utilizadas em FISH são, geralmente, oligonucleotídeos entre 15 e 30 bases com única molécula fluorescente ligada covalentemente ao 5'-terminal. Segundo Moter; Gobel (2000), os fluorocromos mais utilizados em microbiologia são derivados de fluoresceína [(Fluorescein-Isothiocyanate (FITC), 5-(-6-)carboxyfluorescein- $N$ - hydroxysuccimide-ester (FluoX)] e derivados de rodaminas (Tetramethyl-Rhodamine-Isothiocyanate (TRITC), Texas Red) e, mais recentemente, fluorocromos de cianina como Cy3 e Cy5. Os corantes derivados de carbocianinas aumentaram muito a sensibilidade da FISH, mas melhorias ainda são necessárias (AMANN et al., 2001). No Tabela 1 estão relacionados os fluorocromos mais utilizados em FISH com seus respectivos comprimentos de onda e cores visualizadas na microscopia fluorescente.

\section{APLICAÇÕES}

A FISH tem uma grande variedade de aplicações dentro de diferentes campos de investigação, incluindo análise de danos cromossomais, mapeamento genético, toxicologia molecular, genômica comparativa, biologia evolutiva, ecologia microbiana e diagnóstico de doenças (SWIGER; TUCKER, 1996; VOLPI; BRIDGER, 2008). Além disso, pode ser aplicada em detecção de micro-organismos em ambientes complexos como microbiota intestinal, cavidade oral, infecções do trato respiratório, hemoculturas, simbioses e em estações de tratamento de água (Moter; Gobel, 2000).

Na medicina veterinária, a FISH foi utilizada para diagnosticar vários agentes infecciosos tais como Tritrichomonas foetus (Gookin et al. 2010), Lawsonia intracellularis (BOUTRuP etal., 2010; JENSEN et al.,2010a), Pasteurella multocida (Pors et al., 2011a; PORS et al., 2011b), picornavírus (DuRAND et al., 2008), Treponema spp. (NordHoff et al., 2008), Coxiella burnetii (HANSEN et al., 2011), Mycobacterium (LefMAnN et al., 2006) e bactérias do gênero Brachyspira (Boye et al., 1998; JeNSEN et al., 2010b). No trabalho de Boutrup et al. (2010), a técnica de FISH foi também utilizada para determinar que a L. intracellularis, frequentemente encontrada no citoplasma de macrófagos na lâmina própria, era viável, indicando que possivelmente possa existir transmissão e proliferação do microorganismo nestas células, além de enterócitos.

\section{FALHAS DA TÉCNICA}

Moter; Gobel (2000) citaram que, apesar da alta especificidade e sensibilidade dessa técnica, podem ocorrer erros, levando a resultados equivocados. $\mathrm{O}$ principal problema de resultados falsos-positivos ocorre nos casos em que os micro-organismos ou substâncias alvos são autofluorescentes. Alguns fungos, bactérias do gênero Pseudomonas, Legionella, Rhodospirillum centenum, cianobacteria, além de restos inorgânicos, iodo ativado, algumas plantas ou água, podem ter fluorescência natural interferindo na análise da FISH. Tecidos contendo elastina e colágeno, como também eritrócitos ou eosinófilos, podem apresentar certa autofluorescência. Para evitar essas interferências, podem ser utilizados filtros de banda estreita ("narrow band") e sistemas de amplificação de sinal. Segundo esses mesmos autores, outra situação de resultado falso-positivo é a falta de especificidade, que está diretamente relacionada com a sequência de oligonucleotídeo da sonda a ser utilizada. Portanto, ela deve ser analisada minuciosamente realizando testes prévios com amostras controle positivas e negativas.

Resultados falsos-negativos ocorrem nas situações de penetração insuficiente da sonda no interior do micro-organismo, que é dependente da estrutura da parede celular. Bactérias gram-negativas geralmente não apresentam restrições à penetração da sonda por serem permeáveis. Outra situação de resultado falso-negativo é a condição de baixa quantidade de rRNA disponível para anelamento. Embora essa molécula seja abundantena célula, pode variar consideravelmente entre espécies e também 
entre células da mesma espécie. Para detecção de espécies de crescimento lento, é recomendado o uso de sondas marcadas com Cy3 ou marcações múltiplas (MOter; Gobel, 2000).

As sequências alvo de nucleotídeos que contêm entre um e várias centenas de kilobases $(\mathrm{kbp})$ podem ser avaliadas visualmente, no entanto, só é possível diferenciar duas sondas quando se anelam a alvos pelo menos $1.000 \mathrm{bp}$ distantes umas das outras. A diferenciação potencial do método FISH depende do grau de condensação do alvo, ou seja, da disponibilidade de exposição espacial da sequência alvo (LAKATOŠOVÁ; HoleČKOVÁ, 2007), já que a porção r16S possui estrutura bidimensional com regiões mais ou menos accessíveis, que devem ser consideradas no desenho das sondas.

\section{DESAFIOS FUTUROS}

Conforme TANKE et al. (2005), a hibridização in vivo depende da eficácia da sonda fluorescente em penetrar células vivas. Microinjeções, estreptolisina $\mathrm{O}$, scrape-loading, transferência de membrana peptídeo-mediada e eletroporação foram todos aplicados em estudos de hibridização in vivo, e cada método apresentou vantagens e desvantagens. Como as células contêm muitas nucleases, a degradação das sondas de ácido nucleico é um problema sério para estudos de hibridização in vivo. Além disso, não é possível eliminar as sondas em excesso evitando marcações inespecíficas. Portanto, aplicações in vivo têm de ser mais bem desenvolvidas, mas a utilização dessa nova técnica é esperada em futuro próximo.

\section{CONSIDERAÇÕES FINAIS}

Em alguns casos, os patologistas são forçados a utilizar métodos in situ, como a imunofluorescência, para detecção dos micro-organismos, porém, o número de anticorpos disponíveis comercialmente é restrito, e a aplicação desse método requer uma suspeita etiológica prévia. A possibilidade de associar lesões histológicas com análise molecular de genes que abrangem domínios como "gêneros" atendem essa demanda. Outra grande vantagem da técnica é a possibilidade de estudos retrospectivos, pois a hibridização é feita em cortes histológicos fixados em formalina e parafinizados, portanto, materiais de arquivo ou museus representam um estoque único de uma doença específica a ser confirmada (Boye et al., 2006).

Para a patologia veterinária, a determinação da etiologia é de grande importância para caracterizar as lesões histológicas nos casos de infecções, no entanto, geralmente, há a necessidade de isolamento bacteriano tradicional. Portanto, a técnica de FISH propicia um grande avanço em estudos de patogênese, pois permite analisar in situ a infecção pelo agente e sua dinâmica de propagação, bem como estudos sobre a patogenicidade de agentes infecciosos já que podemos observar o padrão de invasão e colonização do tecido.

\section{AGRADECIMENTOS}

Este trabalho faz parte de um projeto de pesquisa financiado pela FAPEMIG. RMCG possui bolsa de produtividade em pesquisa do CNPq.

\section{REFERÊNCIAS}

AMANN, R.; FUCHS, B.M. Single-cell identification by improved FISH. Nature Reviews. Microbiology, v.6, p.339348, 2008. doi: $10.1038 /$ nrmicro1888.

AMANN, R.; FUCHS, B.M.; BEHRENS, S. The identification of microorganisms by fluorescence in situ hybridisation. Current Opinion in Biotechnology, v.12, n.3, p.231-236, 2001.

BAUMAN, J.G.J.; WIEGANT, J.; BORST, P.; DUIJN, P. A new method for microscopial localization of specific DNA sequences by in situ hybridization of fluorchromelabelled RNA. Experimental Cell Research, v.128, p.485490, 1980.

BOTARI, B.; ERCOLINI, D.; GATTI, M.; NEVIANI, E. Application of FISH technology for microbiological. Applied Microbiology and Biotechnology, v.73, p.485-494, 2006. doi: 10.1007/s00253-006-0615-z.

BOUTRUP, T.S.; BOESEN, H.T.; BOYE, M.; AGERHOLM, J.S.; JENSEN, T.K. Early Pathogenesis in Porcine Proliferative Enteropathy caused by Lawsonia intracellularis. Journal of Comparative Pathology, v.143, p.101-109, 2010. doi: 10.1016/j .jcpa.2010.01.006.

BOYE, M.; JENSEN, T.K.; MØLLER, K.; LESER, T.D.; JORSAL, S.E. Specific detection of the genus Serpulina, S. hyodysenteriae and S. pilosicoli in porcine intestines by fluorescent rRNA in situ hybridization. Molecular and Cellular Probes, v.12, p.323-330, 1998.

BOYE, M.; AALBAEK, B.; AGERHOLM, J.S. Fusobacterium necrophorum determined as abortifacient in sheep by laser capture microdissection and fluorescence in situ hybridization. Molecular and Cellular Probes, v.20, p.330-336, 2006. CULLANDER, C. Fluorescent Probes for Confocal Microscopy. Methods in Molecular Biology, v.122, p.59-73, 1999.

DURAND, S.; MURPHY, C.; ZHANG, Z.; ALEXANDERSEN, S. Epithelial Distribution and Replication of Foot-and-Mouth Disease Virus RNA in Infected Pigs. Journal of Comparative Pathology, v.139, p.86-96, 2008. doi: 10.1016/j.jc pa.2008.05.004 
GALL, J.G.; PARDUE, M.L. Formation and detection of RNADNA hybrid molecules in cytological preparations. Proceedings of the National Academy of Sciences of the United States of America, v.63, p.378-383, 1969.

GOOKIN, J.L.; STONE, M.R.; YAEGER, M.J.; MEYERHOLZ, D.K.; MOISAN, P. Fluorescence in situ hybridization for identification of Tritrichomonas foetus in formalin-fixed and paraffin-embedded histological specimens of intestinal trichomonosis. Veterinary Parasitology, v.172, p.139-143, 2010. doi: 10.1016/j. vetpar.2010.04.014.

HANSEN, M.S.; RODOLAKIS, A.; COCHONNEAU, D.; AGGER, J.F.; CHRISTOFFERSEN, A.; JENSEN, T.K.; AGERHOLM, J.S. Coxiella burnetii associated placental lesions and infection level in parturient cows. The Veterinary Journal, v.190, n.2, p.e135-e139, 2011. doi: 10.1 016/j.tvjl. 2010.12. 021.

JENSEN, T.K.; BOESEN, H.T.; VIGRE, H.; BOYE, M. Detection of La wsonia intracellularis in For malinfixed Porcine Intestinal Tissue Samples: Comparison of Immunofluorescence and In-situ Hybridization, and Evaluation of the Ef fects of Controlled Autolysis. Journal of Comparative Pathology. v.142, p.1-8, 2010a. doi: 10.1016/j .jcpa.2009.04.001.

JENSEN, T.K.; CHRISTENSEN, A.S.; BOYE, M. Brachyspira murdochii Colitis in Pigs. Veterinary Pathology. v.47, n.2, p.334-338, 2010b.

LAKATOSOVÁ, M.; HOLECKOVÁ, B. Fluorescence in situ hybridisation. Biologia - Section Cellular and Molecular Biology, v.62, n.3, p.243-250, 2007. doi: 10.2478/s11756-007-0043-2.

LEFMANN, M.; SCHWEICKERT, B.; BUCHHOLZ, P.; GOBEL, U.; ULRICHS, T.; SEILER, P.; THEEGARTEN, D.; MOTER, A. Evaluation of Peptide Nucleic Acid-Fluorescence In Situ Hybridization for Identification of Clinically Relevant Mycobacteria in Clinical Specimens and Tissue Sections. Journal of Clinical Microbiology, v.40, n.10, p.3760-3767, 2006. doi: 10.1128/JCM.01435-06.

LEVSKY, J.M.; SINGER, R.H. Fluorescence in situ hybridization: past, present and Future. Journal of Cell Science, v.116, p.2833-2838, 2003. doi: 10.1242/jcs. 00633.

MOTER, A.; GOBEL, U.B. Fluorescence in situ hybridization (FISH) for direct visualization of microorganisms. Journal of Microbiological Methods, v.41, p.85-112, 2000.
NORDHOFF, M.; RUHE, B.; KELLERMEIER, C.; MOTER, A.; SCHMITZ, R.; BRUNNBERG, L.; WIELER, L.H. Association of Treponema spp. with canine periodontitis. Veterinary Microbiology, v.127, p.334-342, 2008. doi: 10.1016/j.vetmic.2007.09.011.

PLOEG, M. Cytochemical nucleic acid research during the twentieth century. European Journal of Histochemistry, v.44, p.7-42, 2000.

PORS, S.E.; HANSEN, M.S.; BISGAARD, M.; JENSEN, H.E. Occurrence and associated lesions of Pasteurella multocida in porcine bronchopneumonia. Veterinary Microbiology, v.150, p.160-166, 2011a. doi: 10.1016/j. vetmic.2011.01.005.

PORS, S.E.; CHADFIELD, M.S.; SØRENSEN, D.B.; OFFENBERG, H.; HEEGAARD, P.M.H.; BISGAARD, M.; JENSEN, H.E. Pathology, Tissue Metalloproteinase Transcription and Haptoglobin Responses in Mice after Experimental Challenge with Different Isolates of Pasteurella multocida Obtained from Cases of Porcine Pneumonia. Journal of Comparative Pathology, v.145, n.2/3, p.251-260, 2011b. doi: 10.1016/j.jcpa.2011.01.002.

RUDKIN, G.T.; STOLAR, B.D. High resolution detection of DNA-RNA hybrids in situ by indirect immunofluorescence. Nature, v.265, n.3, 1977.

SUI, W.; OU, M.; CHEN, J.; WAN, Y.; PENG, H.; QI, M.; HUANG, H.; DAI, Y. Comparison of immuno histochemistry and fluorescence in situ hybridization assessment for Her-2 status in breast cancer. World Journal of Surgical Oncology, v.7, p.83, 2009.

SWINGER R.R.; TUCKER J.D. Fluorescence in situ hybridization: a brief review. Environmental and Molecular Mutagenesis, v.27, p.245-254, 1996.

TANKE, H.J.; DIRKS, R.W.; RAAP, T. FISH and immunocytochemistry: towards visualising single target molecules in living cells. Current Opinion in Biotechnology, v.16, p.49-54, 2005. doi: 10.1016/j.copbio.2004.12.001.

VOLPI, E.V.; BRIDGER, J.M. FISH glossary: an overview of the fluorescence in situ hybridization technique. BioTechniques, v.45, p.385-409, 2008. doi: 10.2144/000112811.

WOLCOT, M.J. Advances in Nucleic Acid-Based Detection Methods. Clinical Microbiology Reviews, v.5, n.4, p.370-386, 1992.

Recebido em $21 / 7 / 11$

Aceito em 18/7/12 